\title{
Essentials for Information Coordination in Supply Chain Systems
}

\author{
Qing Zhang \\ School of Business Administration, South Central University for Nationalities \\ Wuhan 430074, China \\ Tel: 86-27-6784-3646_E-mail: hust-zq@sohu.com
}

\begin{abstract}
The supply chain plays an essential role for modern companies to retain their competitive advantages in today's business environments. As supply chain members are often separate and independent economic entities, a key issue in supply chain management is to develop mechanisms that can align their objectives and coordinate their activities so as to optimize system performance. Information is a keyword in the coordination. In this paper, we provide a review of coordination of operational information in supply chain which is classified into information types, their impact on supply chain performance, and the policy of information sharing. Then the essentials for information coordination are indicated. In the end, future research direction is pointed out.
\end{abstract}

Keywords: Coordination, Supply chain management, Operational information, Production planning and inventory control

\section{Introduction}

Supply chain management (SCM) has become an important management paradigm. It is to apply a total systems approach to managing the entire flow of information, materials, and services in fulfilling a customer demand (Chase and Richard, 1998). Several seminal studies have identified the problems caused by a lack of coordination, and to what extent competitive advantage can be gained from a seamless supply chain (Forrester, 1961; Lee et al., 1997, pp.546-558; Chen et al., 2000, pp.436-443). Supply chain coordination leads to increased information flows, reduced uncertainty, and a more profitable supply chain .It has become a critical success factor for SCM and effectively improving the performance of organizations in various industries.

From an operational perspective, SCM is to effectively integrate suppliers, manufacturers, warehouses, and stores, so that merchandise is produced and distributed at the right quantities, to the right locations, and at the right time, in order to minimize system wide cost while satisfying service requirements(Simchi-Levi et al.,2000). In this sense, a supply chain coordination mechanism is an operational plan to coordinate the operations of individual supply chain members and improve system profit. When supply chain members are separate and independent economic entities, this action plan has to include an incentive scheme to allocate the benefits from coordination among them so as to entice their cooperation (Li Xiuhui and Wang Qinan, 2007, pp.1-16).

Information sharing between the buyer and vendor in the supply chain has been considered as useful strategies to remedy the so-called bullwhip effect (namely the fluctuation and amplification of demand from downstream to upstream of the supply chain) and to improve supply chain performance (Lee et al., 1997, pp.546-558; Metters, 1997, pp. 89-100). Information exchange is a very important issue for coordinating actions of units. There has been a great deal written on SCM (Li Xiuhui and Wang Qinan, 2007,pp.1-16; Tsay et al., 1998, pp. 299-336; Ganeshan et al., 1998, pp. 839-879; Tan, 2001,pp. 39-48; Sahin and Robinson, 2002,pp.505-535). We focus on coordination from the perspective of information flow that can align the objectives of individual supply chain members.

The paper is arranged as follows: section 2 presents the literature review and the classification regarding operational information in supply chain; section 3 points out the essential elements for coordination of supply chain operational information; section 4 makes some concluding remarks and suggests future research directions.

\section{Review and classification}

\subsection{Information types}

Information involved in literature regarding production planning and inventory control is mostly order and inventory (Lee and Whang, 1999, pp.633-640; Lee and Tang, 2000, pp.626-643; Strace et al., 1998, pp.197-230). Maloni and Beton(1997, pp.419-429) indicated that information about the state of order and the point of Sale are also should be shared. Some researches focus on the information on distributing project scheduling. The distributed project scheduling problem (DPSP) is concerned with configuration and scheduling of multiple projects in a network of enterprises which 
consist of project managers and contractors. Lau et al. (2005, pp.4813-4838) emphasized how to improve the convergence and quality of the solution by taking advantage of inter-enterprise information sharing especially the sharing of schedule flexibility information.

Huang et al. (2003, pp.1483-1517) presented a model of production information, including six categories of production information that are often encountered in the analysis of information sharing. The six categories are product, process, resource, inventory, order and planning.

\subsection{Impact on supply chain performance}

When businesses in a supply chain focus upon the end-user there are many metrics that can be considered. However, they may be aggregated as Service, Quality, Cost and Lead-time (Naylor et al., 1999, pp. 61-73).

There has been a considerable amount of literature on information's impact on cost and service. Angulo et al. (2004 ,pp.101-120) indicated that forecasting information sharing between retailer and supplier can notably increase the ratio of order-fulfillment in the situation of non-stable demand. Gerard and Marshall (2000, pp.1032-1048) studied the value of sharing demand and inventory data in a model with one supplier, $\mathrm{N}$ identical retailer, and stationary stochastic consumer demand. They found that implementing information sharing can reduce cost (consisting of inventory holding cost and back-order penalty cost) up to $13.8 \%$.

Since Forrester discovered the fluctuation and amplification of demand from downstream to upstream of the supply chain, a large amount of literature analyzed this phenomenon. This phenomenon is also well known as bullwhip effect. Several causes have been proposed to explain the appearance of the bullwhip effect, such as demand signal processing which uses forecasting methods not perfectly accurate, gaming among companies when demand exceeds supply, order batching which discretizes orders, and price variations which incite clients to over-order when price is low(Lee et al., 1997, pp.546-558). The consequences of bullwhip effect include higher inventory levels, supply chain agility reduction, decrease of customer service levels, ineffective transportation and missed production schedules. Lee et al. (1999, pp.633-640; 2000, pp.626-643) pointed out that sharing sale data and inventory information can reduce this effect. Chen et al. (2000, pp.436-443) quantified this effect for simple, two-stage supply chains consisting of a single retailer and a single manufacturer. They extended the results to multiple-stage supply chains with and without centralized customer demand information and demonstrated that the bullwhip effect can be reduced, but not completely eliminated, by centralizing demand information.

\subsection{Policy of information sharing}

The policy of information sharing includes essentially information centralization, Vendor Managed Inventory (VMI), and Collaborative Planning Forecasting and Replenishment (CPFR)(Thierry Moyaux et al.,2007). The content of information and the way to share them in the policy is different. Information centralization is the most basic policy of information sharing in which retailers broadcast the market consumption (approximated as their sales) to the rest of the supply chain to reduce bullwhip effect. VMI means that upstream suppliers manage and control downstream inventories based on their production and inventory information. CPFR shares more information (e.g. history sales data and forecast information) than only demand information. This allows the participants to coordinate joint forecasts by focusing on differences in forecasts. They also jointly define plans to follow when specific contingencies occur.

\section{Essentials for information coordination}

\subsection{Identifying the effect of operational information}

It is a key issue to make sure what the accurate information that should be exchanged is when coordination took place. The implementation of information sharing among enterprises needs cost. Tradeoff must be made between cost and obtained benefit. To do this, the effect of operational information must be identified.

The object of information exchange among enterprises is to acquire balance and stabilization of supply chain. From the view of system control, a stable system can be defined like this: a real system in a state of balance could go back to this state after a self-adjust course when it is influenced by external force. Otherwise it is not stable. The balance state of a supply chain is a state in which downstream and upstream enterprises join tightness, production process is persistent, requirements can be fulfilled in time, and the indexes of supply chain performance are fixed in a certain time. This state could be denoted by such indexes as cost of inventory, fulfillment rate of order, and lead time, et al. Combining qualitative analysis and quantitative research is useful to identifying the effect of operational information.

\subsection{Compartmentalization of operational information coordination}

Operational information coordination can be compartmentalized in three ways. Firstly, operational information coordination in supply chain experiences internal coordination and external coordination. Enterprises (especially the manufacturer) should implement internal coordination first. Internal coordination aims to send accurate information in exact form to people who need them for production and management at the right time. Then the supply chain arrives at a new level, and a new instability point would take place. In this point, different modes of information exchange 
between this enterprise and the others in the supply chain might lead the system to various states, presenting inventory cost high or low, response to customer quickly or slowly. To select one of them, supply chain system needs extra information, which provided by other partners.

Secondly, operational information coordination can be compartmentalized according to the span and the depth of information flow. Monolayer information flow is between retailer and distributor, or between distributor and manufacturer, or between manufacturer and supplier. Multilayer information flow enables any enterprises getting the information as needed (refer Fig. 1).

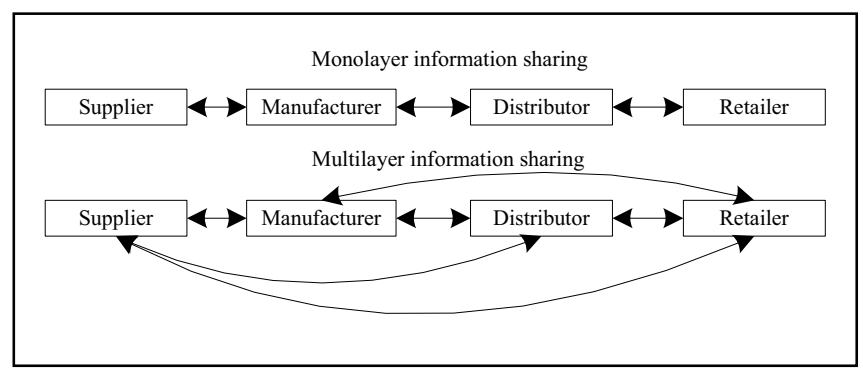

Figure 1. Span of information flow

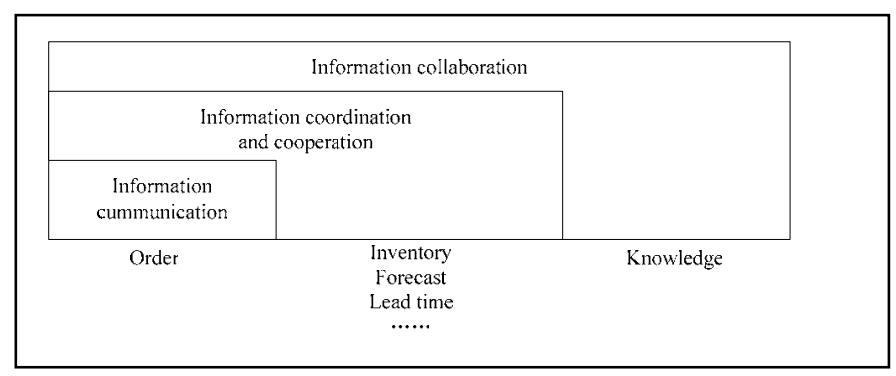

Figure 2. Depth of information flow

The depth of information flow refers to the vertical dimensions in which different information are exchanged (refer Fig. 2). It may consist:

- Information communication. This is the original state of information exchange in supply chain among enterprises. The content of exchanged information is none but order to enable the production activity developed to fulfill demands of customer.

- Information coordination and cooperation. In a volatile market place, competitive advantage needs to be gained from a seamless supply chain. Coordination and cooperation in general have a common goal: to create a transparent, visible information flow through the entire supply chain. So, much more information (e.g. inventory information, lead time information and forecast information) should be shared besides order to acquire mutual benefit, save money and coat, and improve the efficient of operation.

- Information collaboration. With the increasing of uncertainty, supply chain collaboration has been strongly advocated since the mid 1990's under the banner of concepts such as VMI, CPFR, and Continuous Replenishment (CR)( Matthias Holweg et al., 2005, pp. 170-181). Collaboration is the process of shared creation: two or more individuals with complementary skills interacting to create a shared understanding that none had previously possessed or could have come to on their own(Swaminathan et al., 1998, pp.607-632). Collaboration creates a shared meaning about a process, a product, or an event. In this sense, there is nothing routine about it. Something is there that wasn't there before. Information collaboration drives at knowledge creation in supply chain. When collaboration, enterprises in supply chain use information to create something new: new perspectives and new products.

\section{Risks and inspiration of information sharing}

Information exchange in supply chain cannot be carried out freely because enterprises are independent economic entities. From the point of economics view, risks in information sharing are original from the enterprise's behavior of opportunism. From the point of management view, that the desire conflict, hard supervising and possible leakiness of secret information blocks the enterprise's enthusiasm to share information. So the implementation of information sharing needs keeping away risks and inspiration. The measures for former include selecting appropriate partners, discriminating the information from partners, establishing mechanism of risk alert and coordination. The measures for latter include discount policies, inspiriting with price and mode of return. 


\section{Conclusion}

Information coordination is a key approach to achieve supply chain coordination. Information types, their impact on supply chain performance, and the policy of information sharing are significant content in the research of supply chain coordination.

To implement operational information coordination in supply chain, defining the effect of operational information is where the shoe pinches. Combining qualitative analysis and quantitative research is very useful to do this. With the development of artificial intelligence, agent-based modeling method becomes a noticeable way in the research of supply chain coordination (Swaminathan et al., 1998, pp.607-632; Fox et al., 2000, pp.165-188; Allwood and Lee, 2004,pp.101-120). Multi-agent computational environments are suitable for studying classes of coordination issues involving multiple autonomous or semi-autonomous optimizing agents where knowledge is distributed and agents communicate through messages. Since supply chain management is fundamentally concerned with coherence among multiple decision makers, a multi-agent modeling framework based on explicit communication between constituent agents (such as manufacturers, suppliers, distributors) is a natural choice. For future research, we will use this method to modeling information coordination in the supply chain.

\section{References}

Allwood, J. M. and Lee, H. J. (2005). The design of an agent for modeling supply chain network dynamics. International Journal of Production Research, 43(22), pp.4875-4898.

Angulo, A., Nachtmann, H. and Waller, M. A. (2004).Supply chain information sharing in a vendor managed inventory partnership. Journal of business logistics, 25(1), pp.101-120.

Chase and Richard, B. (2000) .Production and Operations Management: Manufacturing and Services. Irwin/McGraw-Hill, 1998.

Chen, F., Drezner, Z., Ryan, J. K. and Simchi-Levi, D. (2000).Quantifying the bullwhip effect in a simple supply chain: the impact of forecasting, lead times, and information. Management Science, 46(3), pp.436-443.

Forrester, J. W. (1961). Industrial Dynamics, Cambridge. MA: MIT Press.

Fox, M. S., Barbuceanu, M. and Teigen, R. (2000).Agent-oriented supply-chain management. International Journal of Flexible Manufacturing Systems, 12, pp.165-188.

Ganeshan, R., Jack, E., Magazine, M.J. and Stephens, P.(1998).A taxonomic review of supply chain management research. In: Tayur, S., Magazine, M., Ganeshan, R. (Eds.), International Series in Operations Research and Management Science, Kluwer Academic Publishers, Norwell, MA, pp. 839-879.

Gerard, P. C. and Marshall, F. (2000). Supply chain inventory management and the value of shared information. Management Science, 46(8), pp.1032-1048.

Huang, G. Q., Lau, J. S. K. and Mak, K. L. (2003).The impacts of sharing production information on supply chain dynamics: a review of the literature. International Journal of Production Research, 41(7), pp.1483-1517.

Lau, J. S. K., Huang, G. Q., Mak, K. L. and Liang, L. (2005).Distributed project scheduling with information sharing in supply chains: part I-an agent-based negotiation model. International Journal of Production Research, 43(22), pp. 4813-4838.

Lee, H. L. and Tang, C. S.(2000). The Value of information sharing in a two-level supply chain. Management Science, 146(5), pp. 626-643.

Lee, H. L., Padmanabhan, V. and Whang, S.(1997).Information distortion in a supply chain: the bullwhip effect. Management Science, 43, pp.546-558.

Lee, H. L. and Whang, S.(1999).Decentralized multi-echelon supply chain: incentives and information. Management Science, 45(5), pp. 633-640.

Li Xiuhui and Wang Qinan. (2007).Coordination mechanisms of supply chain systems. European Journal of Operational Research, 179, pp. 1-16.

Matthias Holweg, Stephen Disney, Jan Holmström and Johanna Småros. (2005).Supply Chain Collaboration: Making Sense of the Strategy Continuum. European Management Journal, 23(2), pp. 170-181.

Metters, R. (1997).Quantifying the bullwhip effect in supply chain. Journal of Operations Management, 15, pp. $89-100$.

Maloni, M. J. and Benton, W. C. (1997).Supply chain partnerships: opportunities for operations research. European Journal of Operational Research, 101, pp.419-429.

Naylor, B., Naim, M. M. and Berry, D. (1999). Leagality: Integrating the lean and agile manufacturing paradigms in the total supply chain. International Journal of Production Economics, 62, pp. 61-73. 
Sahin, F. and Robinson, E.P. (2002). Flow coordination and information sharing in supply chains: Review, implications, and directions for future research. Decision Science, 33 (4), pp. 505-535.

Simchi-Levi, D., Kaminsky, P. and Simchi-Levi, E. (2000).Designing and Managing the Supply Chain: Concepts, Strategies and Case Studies. New York: McGraw-Hill.

Stracer, T. J., Lin, F. and Shaw, M.J.(1998).Simulation of order fulfillment in divergent assembly supply chains. Journal of Artificial Societies and Social Simulation, 10(3), pp. 197-230.

Swaminathan, J. M., Smith, S. F. and Sadeh, N. M. (1998). Modeling supply chain dynamics: A multiagent approach. Decision Sciences, 29(3) pp.607-632.

Tan, K.C.(2001).A framework of supply chain management literature. European Journal of Purchasing and Supply Management ,7, pp. 39-48.

Thierry Moyaux, Brahim Chaib-draa and Sophie D'Amours. (2007).Supply chain management and multiagent systems: An Overview. [Online] Available:http://www.damas.ift.ulaval.ca/publications/moyaux06chap1.pdf. (July 7, 2007).

Tsay, A.A., Nahmias, S. and Agrawal, N. (1998). Modeling supply chain contracts: A review. In: Tayur, S., Magazine, M., Ganeshan, R. (Eds.), International Series in Operations Research and Management Science, Kluwer Academic Publishers, Norwell, MA, pp. 299-336. 